\title{
Education and Armed Conflict in Sudan and South Sudan: The Role of Teachers in Conflict Resolution and Peace Building
}

\author{
Anders Breidlid \\ Oslo Metropolitan University, Norway \\ Email: anders.breidlid@oslomet.no
}

\begin{abstract}
This article discusses the relationship between education and armed conflict in Sudan and South Sudan, and particularly the role of teachers in peace and reconciliation efforts. The periods covered are the North-South civil war from 1955 to 2005, the interim period between 2005 and 2011 with the Comprehensive Peace Agreement and the current civil war in South Sudan which started two years after South Sudan's independence in 2013.

The article shows that teachers are not always promoters of peace and reconciliation, and that their teaching in class to a large extent is context-dependent.

The teachers in the Islamic schools during the first civil war had few options but to teach according to the Islamic curriculum and thus cemented the self-Other dichotomy between the Northerners and the Southerners in the conflict-ridden country. Moreover, the article shows that the teachers in the liberation areas in the South during the first civil war chose deliberately a confrontation strategy against their oppressors from the North that coincided with the resistance war.

In the civil war inside South Sudan from 2013 a different teaching pattern emerged where the teachers discussed openly the atrocities of the North during the first civil war, but applied an avoidance strategy in class when teaching about the civil war inside the South. It was perceived to be less of a dilemma to teach contemporary history without touching upon domestic conflict and ethnic rivalry than to teach about conflicts in the South which seriously undermined any idea of social cohesion. Undoubtedly, the teachers felt strongly that it was necessary to treat history teaching carefully, and that there is a fine line between what should and should not be told. There was a perception among teachers that debating the domestic civil war might cause unrest and conflict in class whereas any discussion of the South-North war would not since very few, if any of the students had any allegiance to the North and the Islamic discourse.

The article thus raises the question of the relationship between the teachers' solutions to these dilemmas and education's role in conflict situations.
\end{abstract}

Keywords: Education, teachers' role and armed conflict, peace and conflict resolution, different educational discourses

\section{Introduction}

This article analyses the relationship between education and armed conflict in Sudan and South Sudan, and discusses in particular to what extent teachers contributed to peace and reconciliation in their different roles as educators in relation to the North-South civil war and the current civil war in South Sudan.

The history of conflict in Sudan and the southern part of the country in particular is unfortunately long and protracted. The first civil war between the North and the South lasted, with certain intermissions (e.g. the cease-fire between 1972 and 1983), from 1955 to 2005. The Comprehensive Peace Agreement (CPA) was signed in 2005 between the two warring parties and lasted until July 9, 2011 when South Sudan became an independent nation, the newest nation on the planet. The domestic conflict inside South Sudan started in December 2013 and, despite certain intermissions, is still ongoing.

\section{Education, Teachers and Peace Building}

Research shows that education can contribute to peace and reconciliation as well as to instigating 
conflict (Bush and Saltarelli, 2000; Sommers, 2002; Vriens, 2004, Davies, 2004; Paulson, 2011). Education may thus seem to play a somewhat contradictory role in conflict situations since (re)building schools, recruiting teachers, and returning children to classrooms may help reduce the causes of conflict (Collier, 2006; McEvoy-Levy, 2006). However, schools may also be one of "the most successful instruments for the ... dissemination of militarism" (Vriens, 2003, 71). Moreover, Sommers (2002, 8) states that "many who conduct modern wars are expert at using educational children" (see also Breidlid 2010; Skårås and Breidlid, 2016).

Thus education can be part of the problem as well as part of the solution. The question is therefore to what extent education and teaching in war-torn contexts aggravate or ameliorate conflict.

In its review of the empirical, quantitative literature on the relationship between education and civil conflict, the Centre for the Study of Civil Wars (CSCW 2011) concludes that:

- Increasing educational levels overall has pacifying effects.

- Rapid expansion of higher education is not a threat.

- Education inequalities between groups increase conflict risk.

- The content and quality of education might spur conflict.

Undeniably, conflict inevitably means that children and young people in conflict areas are more prone to be out of school than children and youth in peaceful areas and regions. When the opportunity of education has been lost due to conflict, it is not, as Smith and Vaux, 2003, 1) state, "not just a loss to the individual, but a loss of social capital and the capacity of a society to recover from the conflict." According to a recent UNESCO report children in conflict-affected countries

make up $22 \%$ of the world's primary school aged population, yet they comprise $50 \%$ of children who are denied an education, a proportion that has increased from $42 \%$ in 2008 ... Of the 28.5 million primary school age children out of school in conflict-affected countries, 12.6 million live in sub-Saharan Africa, 5.3 million live in South and West Asia, and 4 million live in the Arab States. (UNESCO, 2013).

In South Sudan half of the school population is out of school (UNICEF, 2016).

Teachers' role in peace building is complex and sometimes contradictory. Their role can be both passive or dynamic and active based on agency. They can both promote peacebuilding through social cohesion and inclusiveness in the classroom, but can also effect conflict by perpetuating or emphasizing ethnic, religious and social differences in class. The lines between the two are not always clear and the same teacher may play out both roles simultaneously in different moments and contexts. This is because teachers do not exercise their peacebuilding agency in isolation from their surroundings and their agency both influences their surrounding and is influenced by it (O'Sullivan et.al., 2002; Weldon, 2010; Welmond, 2002). The teachers' role is very much dependent on context, and there is reason to question generalized statements about teachers' role in peace building. For example, Novelli and Sayed (2016) are in principle right that training of teachers is essential to ensure social cohesion, equity and peace in the classroom and that an important tool for teachers is the curriculum and the textbooks in order to secure social cohesion (Novelli and Sayed, 2016). The issue is, however, that in a Sudanese and South Sudanese context, there has hardly been any space for developing professional competencies among teachers, and the curriculum during the first civil war was actually a document generating resistance among South Sudanese. Moreover, the new nation in South Sudan has not managed to launch a curriculum that addresses the challenges of the new nation. Instead, teachers during the current internal civil war from 2013 depend on an outdated version from 2007. In addition, textbooks were also objects of resistance during the North-South war, and in the current situation textbooks hardly exist in the new nation.

As I will try to show in this article teachers are therefore not given the tools necessary to promote reconciliation and peace, and are therefore often selective and strategic actors in an often politicallycharged context (Lopes Cardozo \& May, 2009).

\section{Theoretical Considerations}

In this article I use social cohesion theory and attribution theory to discuss my findings. The two theories seem to capture the key points in this article which relate to interdependence between an ethnic and religious group on the one hand (social cohesion) and the self-Other dichotomy explained in 
attribution theory on the other.

\subsection{Social Cohesion Theory}

Although there is no single definition of 'social cohesion' it is often used to describe connections and relations between social units such as individuals, groups, associations as well as territorial entities (McCracken, 1998). Moreover, it refers to interdependence between members of the society where terms like loyalty, unity and solidarity are important. According to the UNICEF Peacebuilding, Education and Advocacy Programme (PBEA) social cohesion is defined as:

the quality of coexistence between the multiple groups that operate within a society [...] along the dimensions of mutual respect and trust, shared values and social participation, life satisfaction and happiness as well as structural equity and social justice (UNDP Act, July 2013 cited in UNICEF, 2014a).

Successful social cohesion in a society or a nation exists where social relations are strong, values and a common identity are recognized by the majority of the people, and where there is a sense of belonging and trust in the population. In other words, social cohesion in a society means that values are shared, and that there is an emphasis on social inclusion (Tawil \& Harley, 2004). Integration of individuals and group members in the society at large are central aspects of social cohesion and the basis for conflict resolution (Green, Janmaat, \& Cheng, 2011). Social cohesion implies, according to Jenson (1998) five dimensions: 1) belonging in terms of values, identity and culture, 2) inclusion and 3) participation in terms of political and social involvement, 4) recognition in terms of respect and tolerance and 5) legitimacy in relation to institutions or governments that are arbitrators or peace-makers in a conflict situation. Social cohesion often implies, however, that minority groups and their values and culture are not accepted by the majority population and that there is pressure to adhere to majority values. Lack of social cohesion thus means often a failure of cultural diversity and thus an unwillingness to accommodate difference or 'the Other,' i.e. resistance against accepting groups of people with a different cultural and religious set of values than the majority. It means a failure and unwillingness to accept difference which leads to polarization among members of the society/nation, a weak sense of belonging, unity and inclusion and a lack of trust among or between the citizens. Instead there is an imposition of specific hegemonic cultural and religious values causing conflict and lack of unity and loyalty.

This concept is very much related to power relationships where the hegemonic power attempts to deny the inclusion of minority groups' identity and historical narratives. In education the curriculum and textbooks reflect in most countries the ideology of the hegemonic power, but ideological uniformity is more articulated in countries with little acceptance for dissenting voices.

\subsection{Attribution Theory}

Attribution theory helps to explain how parties on both sides of a conflict "attribute" various causes of the strife. While "dispositional attributions" refers to causality ascribed to internal or innate factors, "situational attributions" refer to external factors outside the control of the agent (Heider, 1958). This means that dispositional attributions refer to behaviour attributed to the innate nature of self and Other (dispositions). This in turn makes behaviour more predictable and gives a sense of control. On the other hand, dispositional explanations may blur the complexity and ambiguity of "reality," creating versions of "reality" that are not easily subject to change. The "fundamental attribution error" tends to be augmented when the observer dislikes the Other and the Other's behaviour affects the observer's own life. Situational attributions, on the other hand, are context dependent and positions are dependent on how the observers react to specific situations.

\section{Methodology}

The article is based on a long-term study which encompasses fieldwork in 2002-2004 during the civil war between the Khartoum-based government in Sudan and the Sudan People's Liberation Army (SPLA) in Yei River County, Eastern Equatoria, South Sudan, field work in the Khartoum area in 2002 and 2003 
(3 months' every year) and shorter visits to Sudan were undertaken by the author after the Comprehensive Peace agreement (CPA): to Khartoum and Malakal (Southern Sudan) in 2006, to Juba (Southern Sudan) in 2007 and to Khartoum and Malakal in 2008. The field work during the civil war between the Khartoum government and SPLA was conducted by 2 well-trained Sudanese field workers, 3 Norwegian research assistants and the author. In the North 1 Sudanese field worker as well as 2 Norwegian research assistants helped out.

Moreover, another fieldwork was undertaken during the internal civil war in South Sudan after South Sudan achieved independence in 2011.

In this article the focus is on the qualitative interviews with teachers and pupils. In the field work before independence 41 pupils and 54 teachers were interviewed in South Sudan and 23 teachers and 18 pupils from South Sudan living in the Khartoum area were interviewed. Informants were selected using a purposive sampling approach to collect data from teachers and pupils of different ethnic groups. In the South, Bari, Kakwa, and Dinka informants living in Yei were interviewed; in the North, Southern migrants from the same tribes as in the South and the members of the Lotuka tribe were interviewed (Breidlid, 2010).

The formal interviews with teachers and pupils were conducted by using interview guides containing open-ended and semi-structured questions (Kvale, 1996, 84 and 189). All formal interviews were audiotaped and transcribed. Since our focus of the interviews was the teachers' role in conflict we enquired about their views on the importance of education and teaching in conflict resolution besides obtaining insights into the classroom situation, the subjects taught and the relevance of the curriculum.

In addition, the research team also conducted informal interviews which were used to both cross-check the information from the formal interviews and to gain new information. The data were coded and used in our analyses of the various types of data.

The data from the internal civil war in the South were based on two periods of focused ethnographic fieldwork undertaken by the author's $\mathrm{PhD}$ student and a small research team. The first period lasted from September to December 2014 (Skårås, 2016) and the second from July to September 2015 and was what can be termed focused ethnography which intensifies the data collection over a short-time period due to limited access and security. In conflict settings, there is a sense that focused ethnography is specifically well suited to get an in-depth understanding of teaching and learning in schools (Knoblauch, 2005; Millen, 2000; Pink \& Morgan, 2013).

Based on qualitative research 17 teachers and 28 students were interviewed, classroom observation was conducted and 69 written student essays from six secondary schools in Narus and Juba were analysed. Both Nuer and Dinka ethnic groups were included in the sample together with a number of other ethnic groups. (Skårås and Breidlid, 2016). Convenience sampling was carried out since any student who had time and wanted to contribute to the study for an interview was selected. Due to lack of textbooks and other teaching material the role of the teacher was very central. The use of video observation in four of the six schools with a focus on the teacher was therefore an important data collection method in addition to interviews and observations. The data was transcribed and coded and later used with specific reference to theories relevant for the findings.

\section{The issue of representation}

To state the obvious first: To do fieldwork in such a marginalised area as Sudan and South Sudan is not without its problems. Besides the obvious security challenges as well as certain infrastructural and logistical problems during our field works in the war zones, access to key informants in Khartoum was often problematic due to lack of permits, political foot-dragging etc., thus causing delays and inefficiency in the planned field work programme.

Moreover, we as researchers came into the area with a set of assumptions that we wanted to explore. As Geertz $(1995,94)$ states:

Field research in such times, in such places, is not a matter of working free from the cultural baggage you have brought with you as you enter, without shape and without attachment, into a foreign mode of life. It is a matter of living out your existence in two stories at once.

Also, as Mc Laren $(1995,274)$ reminds us of, researchers 
undertake their projects not just in the fieldsite, but within a field of competing discourses that help structure a variated system of socially constructed human relationships and where the field site may be considered the site of the researcher's own embodiment in theory/discourse and his /her own disposition as a theorist, within a specific politics of location.

It is with these considerations in mind that we as researchers are faced with the challenge of recovering meaning. The issue at stake is that of representation.

The present text is thus based on and constructed as a result of the perceptions of the many participants and the multiplicity of voices in the field sites as we interpreted them. (For an excellent discussion of research and indigenous people, see Tuhiwai Smith, 1999). Despite the multiplicity of voices, however, the text is not characterized by multiple or fundamentally different stories inside the territorial and imagined communities of the North and the South, as the perception of the North as represented by the NCP, by the people in the Yei region in the South or by Southern migrants in and around Khartoum was interpreted as overwhelmingly unanimous. ${ }^{1}$ Similarly Northern teachers' perceptions of Southerners were perceived as equally uniform, even though a distinction can be drawn between representatives of the hegemonic state apparatus of the riverein elite and marginalized Muslim teachers. ${ }^{2}$ There is a sense, then, that our interpretations, even though socially constructed, reflect deeply ingrained attitudes, exemplified in the apparent persistence of the dominant discourse of resistance during the first civil war in Southern Sudan, unrivalled as it were with other discourses. Even though we might agree with Mc Laren's claim that we as researchers "construct and are constructed by the discourses we embody and the metaphors we enact" the unanimosity of the data as analyzed by both native and foreign researchers were also validated through the practices of the people involved in the two civil wars.

\section{Education during the First Civil War}

During the first civil war, which in effect ended in 2005 with the Comprehensive Peace Agreement (CPA), there were huge educational differences between the two warring parties, the southern part of Sudan and the North of Sudan. In the North 78 percent of the pupils took the eighth-grade exam whereas in the South only about 30 percent of an estimated 1.06 million school-age children were enrolled in primary school (JAM 2005b, 176). The situation in the southern part of the country was indeed very serious, since enrolling in school does not guarantee graduation. The situation was particularly bad for girls; at that time a girl was three times more likely to die in childbirth than to enter Grade 8 (Global Partnership for Education, 2012).

\subsection{The Education Discourse in Sudan}

The education discourse in Sudan and the big cities in the South up to the CPA in 2005 was an Islamist discourse with mono-ethnic and mono-religious characteristics. Based on the ideological fundamentalism of the Islamic state of Omar al-Bashir the dominant discourse was (and still is) a discourse where power and Islamic theocracy sanction each other and is reflected in the National Curriculum.

The knowledge production inherent in the National Congress Party (NCP) policy on education was to prioritize knowledge of Islam above all other knowledge. Nothing existed outside of Islam and thus, "everyone is potentially a Muslim. And since nothing exists outside of Islam, the mode of convergence ... is Islam" (Simone, 1994, 143). The aim of Islamist education discourse was "to strengthen faith and religious orientation and conviction in youngsters so that they may become free, Allah-devoted and responsible persons" (al-Bashir, 2004, 55).

\footnotetext{
${ }^{1}$ Even though certain Southern peoples, such as the Mundari and Toposa, were divided in their loyalties between the government in the North and the liberation movement (see Johnson, 2007, 127), the Southern resistance against Muslim Arab incursion was, as is discussed in more detail later, massive.

${ }^{2}$ While the feeling of superiority is deeply embedded in the riverein Muslim elite in and around Khartoum which has been in power for more than a century, Muslim informants outside the city centre voiced a much more conciliatory sentiment towards the Southerners, not the least because these informants also felt themselves marginalised by the very same elite.
} 
An analysis of the textbooks and teaching material in the primary schools which the teachers had to adhere to showed that Muslim Arabs figured overwhelmingly, both in the texts and in the pictorial material (Oyenak, 2006). Moreover, Arabic was the language of instruction. Education cannot, in an Islamic state, be removed, as Reagan states, "from its religious context, and it is in the Qu'ran that educational thought should be grounded" (Reagan, 1996, 130). The educational policy of the Khartoum regime can be summed up in the following way:

The use of one national curriculum throughout the educational system; the use of Arabic as the sole medium of instruction, with English taught as a subject; the full control by the government over all schools in the country; the centralization of educational planning to be the exclusive domain of the Federal Ministry of Education; and the consolidation of religion and religiosity in, and through, the educational system (Kenyi, 1996, 15).

Founded on a self-Other dichotomy the National Curriculum solidified and cemented in many ways identities along ethnic and cultural lines rather than creating social cohesion and a common identity. While the riverine $^{3}$ Muslim elite felt a sense of belonging to the curriculum in terms of inclusion, recognition and legitimacy there was nothing in the curriculum that attempted to include or recognize non-Arabs and non- Muslims. On the contrary, everybody was supposed to be integrated and succumb under the values of the curriculum from the Khartoum government. The teachers teaching in schools around Khartoum where both Muslims and southern Christians attended were trained in the NCP curriculum, and as noted, Arabic was the medium of instruction. Clearly this alienated the pupils from the South both linguistically and epistemologically.

The Islamists insisted on the unity of all existence and the totality of Islam, but they confirmed at the same time the Qur'anic differentiation between believers and infidels thus marginalizing people of other faiths or beliefs.

The teachers were thus linked to an education system which defied modernity's separation between the secular and the spiritual. Due to the internal, authoritarian logic of the Islamic educational discourse the idea that teachers should promote social cohesion across ethnic and religious boundaries was nonexistent. Any attempt on the part of the teachers to generate shared values, belonging, inclusion and legitimacy on the basis of an Islamist education discourse was therefore doomed to fail. Antithetical to any idea of social cohesion the teaching instead increased tension and polarization. Briefly put, the teachers in NCP controlled areas did not contribute to peace and reconciliation in their different roles as educators in relation to the North-South civil war

Since more than one million Southerners (predominantly Christians) were living in the North prior to the CPA (primarily in IDP camps in the riverine, Khartoum area) due to the conflict in the South, there were repeatedly conflicts and tensions between the Muslims and Christians in the society and in the schools run by teachers from the South in the refugee (IDP) camps. One teacher in the IDP camp in the Khartoum area stated: "The National Curriculum is planned by few people. It is not designed according to the whole area. It is designed, just for Muslims, not Christians." Very few of our Southern teacher informants in the Khartoum area had any form of professional teacher training, and relevant textbooks were few and far between.

The epistemological and cultural inequality in the education system thus promoted political unrest and instability where political and civil liberties were pushed under the carpet in direct opposition to peacebuilding efforts and completely absent in the Khartoum government's curriculum. Instead, the education discourse dictated by power and ideological hegemony was one of the reasons for conflict.

The whole rhetoric around the curriculum made in Baht Al Ruda, the Sudanese Curriculum Centre, was moreover couched in an ideology of attributions where the superiority of the Islamic culture and religion was explained in terms of dispositional, innate attributions. The Other, on the other hand, was also perceived, if not always explicitly, in terms of negative dispositional attributions. To base an education discourse on such an ideology is at best provocative to those who were Othered, and clearly not an adequate learning space for them. As one Southern teacher stated: Teaching in these schools in and around Khartoum is meaningless for Southerners" (2003). The Southern teachers who were forced to teach in the $\mathrm{NCP}$ areas were in both open and more subtle ways trying to resist the imposition of the $\mathrm{NCP}$ curriculum, and advocated a non-Islamic content whenever possible. However, as the teachers were

${ }^{3}$ Most members of the ruling elite in postcolonial Sudan, come from the riverine areas of central Sudan. 
strictly controlled by the $\mathrm{NCP}$ and had to follow the NCP curriculum, exit points from the Islamic imposition were indeed few.

The imposition of the Islamic discourse and the lack of appropriate educational opportunities was one of the reasons why youth in the South readily took up arms (Salaam and de Waal, 2001, Breidlid, 2006).

As one of my informants stated: "Denial of education is one of the main causes of the war" (2003).

The long civil war which ended in 2005 was thus an ideological, religious and epistemological war of visions where educational policy was an important aspect (see Breidlid, 2010).

\subsection{The Resistance against the Islamic Education Discourse}

The total imposition of Islamic faith and world view was thus vehemently rejected by the Southern Sudanese who are predominantly Christians or believers in traditional religions. They viewed the pervasiveness of Islamic knowledge in education as an authoritarian imposition of a completely alien religion and world view which had to be fought at all costs.

The resistance by the Southern People's Liberation Movement/Army (SPLM/A) against the various Khartoum regimes from 1954 was thus due to what was perceived by most Southerners as an oppressive, exclusivist Islamist ideology against the South. The vision of a secular education system where religion, and primarily Christianity, is a subject rather than an all-encompassing ideology influencing all subjects was introduced during the civil war in the liberated areas in the South, and the intention was to introduce the same secular education system throughout the Southern states after liberation. Moreover, its Muslim-Arab bias was to be replaced by a syllabus where non-Arab values would play a more central role. This was an important measure in an attempt to establish a cohesive identity in the South across ethnic boundaries where belonging to a Southern nation state was in focus

The education discourse in the liberated areas in the South during the North-South civil war was therefore modernist and secular of nature with either a local language or English as medium of instruction, a fundamental ideological and epistemological reversion of the Islamic discourse in the North. Clearly the Southern discourse was supported by Western powers in their attempt to stem the flow of Islamist influence to the southern part of Sudan and even to East Africa.

According to many of our teacher informants the modernist educational discourse was viewed as an important tool against northern religious and political imposition. The teaching in the liberated areas, particularly in history, was marked by explicit references to the oppressive policies by the Arab, Muslim Khartoum government and how it destroyed the southern region in terms of culture, religion and education. As one teacher in the IDP camp in the Khartoum area stated: "The National Curriculum is planned by few people. It is not designed according to the whole area. It is designed ... just for Muslims, not Christians" (2003). In the same vein, a parent from the South mentioned, "All songs are in Arabic. There are no tribal traditions, no vernaculars, no songs in my school" (2003). The teachers thus reversed the self-Other perceptions in the North where the problematic aspects of the Islamic culture and religion was explained in terms of negative dispositional, innate attributions. However, there is reason to believe that the impact of education in the liberated areas- despite its ideological and epistemological fervour and zeal- had been greater in terms of social cohesion and in reducing negative attributive perceptions between ethnic groups in the South if the education quality had been of a higher standard. Admittedly the quality of education in the liberated areas was extremely low, not the least due to untrained teachers and lack of the most basic teaching material. There is however no indication in our field notes that the few trained teachers that were actually teaching in the liberated areas had a different ideological attitude to Islamic imposition. Promoting reconciliation in a context of massive military and religious and cultural domination was never an issue, whether the teachers were trained or untrained. As a matter of fact there was a very cohesive, unanimous negative attitude both in the schools and on the battlefields to the intruders from the North (Breidlid, 2010).

\section{The CPA Period}

After the war ended in 2005 the number of primary level pupils in the South increased from 700,000 in 2006 to 1.6 million in 2009. Moreover, The Alternative Education System (AES) established in Southern Sudan in 2005 where eight grades were compressed into four years provided an opportunity for older 
youth to receive education. More than 217,000 students were enrolled by 2009 meaning that the primary school gross enrolment rate (GER) increased from an estimated 21 percent in 2000 to 72 percent in 2009 (World Bank, 2012). The period after the CPA thus experienced a rapid growth in the attendance rate in primary schools, but the number of pupils in the upper grades was small due to massive drop out in the earlier grades, with only 26 percent for grade 6 and 8 percent for grade 8 (World Bank, 2012). Moreover, an estimated one million children were out of school.

\section{Independence and the Civil War in South Sudan}

South Sudan became the planet's newest nation on July 9, 2011, but post-independence euphoria ended after a two-and-a-half-year period when hostilities broke out inside the new nation on December 152013. Despite several cease-fires the war is still continuing (July 2019). The immediate reason for the outbreak of the civil war after South Sudan's independence was the ouster of Vice President Riak Machar from the Government of South Sudan (GoSS) in June 2013. The Sudan People's Liberation Army (SPLA) was thus split in two with the former allies on opposite sides of the front line. Riek Machar took up arms against forces loyal to the Government of South Sudan (GoSS) headed by President Salva Kiir. Initially, the civil war was perceived as an ethnic conflict where the Dinkas predominantly supported Salva Kiir and the Nuer supported Riak Machar, but the picture today is not so easily defined along clear-cut ethnic lines.

The consequences of the war for the civilian population have been devastating as there have been attacks on schools, hospitals, churches, mosques, and United Nations bases; and there is reason to believe that violations of international human rights and humanitarian law have been committed by both parties in the conflict.

The International Crisis Group (ICG) estimates that the death toll people since the outbreak of the civil war in 2013 could be between 50,000 and 100,000 (ICG, 2014). Well over 50,000 people have been killed and more than 1.6 million have been internally displaced since civil war broke out in South Sudan. Due to the same war 1.88 million South Sudanese are internally displaced (IDPs), and 215,000 are living in UN Protection of Civilians sites (OCHA, Sept 2017). In addition, the total number of South Sudanese refugees living in neighbouring countries like Ethiopia, Kenya, Sudan, DR Congo, CAR and Uganda is 2.1 million, approximately half of them living in Uganda. In the period from January to September 2017 alone the number of new refugees was 637,000 (OCHA, Sept 2017). Moreover, the threshold for return seems to be very high and what is particularly worrying in an educational context is that $63 \%$ of the refugees are under the age of 18 and that education is not prioritised in the humanitarian response.

\subsection{The Self-Other Dichotomy}

The current civil war operates within a framework similar to that of the previous war between the North and the South in the sense that there is a strong perception of a self-Other dichotomy between the warring parties. In contrast to the North-South war, the current civil war is not based on religious antagonism, but to a large extent based on ethnic animosities (at least initially) and personality and power issues (see Breidlid et al, 2014). The perception of the Other is very much the reason for the conflict, how the Dinka perceive the Nuer and vice versa, and where the perceptions are characterized to a greater extent by dispositional rather than situational attributions. It means that specific situations that could have caused changes did not fundamentally change the basic perceptions of the Other. It was the innate nature (dispositions) of the Dinka and the Nuer that was perceived by the warring parties to be the main reason for the conflict. Admittedly the war on the ground today is much more complex, with the ethnic lines of demarcation sometimes blurred since there are Nuer fighting together with the Dinka and vice versa, even though the basic conflict can still be characterized along ethnic lines between the two biggest ethnic groups in the country. In the new nation called South Sudan the hostile climate and the almost complete lack of social cohesion across ethnicities meant that dimensions of mutual respect and trust, shared values and social participation, were more or less non-existing. Instead a raw power struggle between old leaders without visions is taking place with massive suffering among the local population. Clearly the new South Sudan can today be characterized as a failed state. 


\subsection{Education inside South Sudan}

Undoubtedly, both civil wars have had huge negative consequences for education in the southern part of Sudan, the now South Sudan. Whereas the civil war between the Khartoum government and the southern part of the country was fought by the Southern rebels on the basis of political, religious, political and educational liberation, the current internal civil war is apparently devoid of ideological and educational vision.

As a matter of fact, education and the nature of the educational discourse was not an issue of contention when the domestic civil war broke out in 2013. In terms of epistemology the education discourse was solidly based on a Western framework, with no explicit anti-Arab or anti-Muslim stance.

For those pupils who do not live as refugees outside the country the domestic education situation is complex and very difficult. The fact that more than one million of South Sudan's primary school age children (out of a total of two million) are out of school means that many out-of-school children are recruited to armed groups and thus risks sustaining the ongoing conflict or fuelling new conflicts in the country.

Even before the war broke out, education indicators were already extremely low in South Sudan with the lowest schooling coverage for education in all sub-sectors (pre-primary, primary and secondary) in the region (South Sudan Ministry of Education's 2011 Statistical Yearbook). The education situation is made even worse by a dramatic lack of qualified teachers. 61.2 percent of working teachers were untrained and salaries are very irregular. Moreover, there was a chronic lack of textbooks and adequate facilities, with an estimated shortage of more than 25,000 classrooms where teaching can take place (UNICEF, 2011). The civil war has made schools unsafe sites for learning. The November 2016 national assessment conducted by the Education Cluster showed that $31 \%$ of primary schools have suffered one or more attacks since December 2013, and $25 \%$ of the primary schools which were open at any point since 2013 were found to be non-functional. Moreover, lack of food is one of the main reasons for student drop out and is primary cause for non-attendance (South Sudan Education Cluster, 2016).

The completion rate in primary schools was less than 10 per cent even before the current civil war, one of the lowest in the world, and probably lower during the current civil war. It therefore goes without saying that the quality of education and learning outcomes are disastrous. Moreover, there are huge gender disparities. While the gender ratio among those attending primary school in 2013 was $38.9 \%$ female and $61.1 \%$ male only a small number (approximately one per cent) of girls graduated from primary schools (Education for All 2015 National Review Report: South Sudan, UNESCO).

\subsection{The South Sudan Curriculum Framework}

Prior to the launch of the National Curriculum Framework in 2015 (a curriculum framework which still has not been introduced in the schools), there was a fairly chaotic curriculum situation in South Sudan. Some schools were using the South Sudan curriculum from 2007 while others were using curricula from Uganda, Kenya, Ethiopia, Sudan, or a hybrid depending on what resources were available.

While the situation on the ground is very difficult, the Government of South Sudan had and still has ambitious and quite unrealistic plans for education. In 2012, a year before the civil war broke out, the Government of South Sudan passed the General Education Act which stipulated that "primary education shall be free and accessible to all citizens of South Sudan without discrimination on basis of sex, ethnicity, race, religion, and health status or disabilities" (EFA 2015, 5). Moreover, the government developed the five year "General Education Strategic Plan, 2012-2017" (GESP, 2012) with 2022 set as the target year for achieving the Education for All and Millennium Development Goals (MDGs) and achieving a fully literate society by 2040 . However, due to the still ongoing civil war the strategic plan is worth not much more than the paper it is written on.

The first comprehensive national education curriculum for South Sudan is characterized by the Ministry of Education Science and Technology to be "a complete, harmonized, and recognized curriculum in line with regional and international education standards" and was launched under the theme: "Harmonised Education Service Delivery for Nation building, Peaceful Co-existence and Lifelong Learning for All" (UNICEF, 2015). It is moreover stated that the key aims of the curriculum are: "Good citizens of South Sudan who are: ... committed to unity, democracy, human rights, gender equity, peace and reconciliation" (5). This is reiterated later when the values of the curriculum are described: "Human 
rights and gender equity. Respect and integrity. Peace and tolerance" (8). Moreover, under "Principles" it says: "A spirit of hope, respect, peace, reconciliation, unity and national pride, democracy and global understanding" (8). At the same time the Curriculum Framework underlines "diversity and respect for people of different races, faiths, communities, cultures and those with disabilities" (x). According to Maphalala (2015) the curriculum framework is described as the key to South Sudan's national identity:

The curriculum is designed to help young people learn about their shared national identity. It supports key values for the country including justice, democracy, tolerance and respect; these values need to become an essential part of young people's lives. Human rights and gender equity must also become the norm. Young people's understanding of, and commitment to, these values is essential to the country's future, and that's why they are mainstreamed throughout the curriculum.

This comprehensive national education curriculum for all basic education levels in the country is/was thus an effort to provide access to learning for all South Sudanese and promote social cohesion, a common unity and national identity, but as the war continued it was completely unrealistic and unachievable.

Similar to the situation in the liberated areas before 2011 the education discourse reflected in the syllabus for primary and secondary schools from 2007 and the Curriculum Framework of 2015 is secular of nature with English as a medium of instruction where different ethnicities are gathered in the same classroom. In more mono-ethnic contexts the indigenous language is used as medium of instruction up until grade 4.

\section{Teachers in a Conflict-Ridden Terrain}

What is of particular interest in our context is how the teachers behaved as educators in relation to the North-South civil war and the current civil war in South Sudan, and particularly how the content of the history teaching was dealt with. Admittedly teaching history with hardly any teaching material available is of course a very challenging task. ${ }^{4}$

In a study from 2016 (Skårås and Breidlid, 2016) it was found that classroom teaching on the current conflict is quite different from the teaching about the North-South conflict. The teachers teaching about the civil war between the North and the South were explicit about the South's grievances against the North's oppressive policies. The teachers in the classroom re-echoed what was the typical attitude on the ground in South Sudan by expressing in no uncertain terms the negative sentiments against the Northerners and their aggressive and brutal ideological and military policies. Moreover, the historical and current legacy of the Khartoum government was explained in terms of a self-Other dichotomy where the oppressive behaviour of the North was almost exclusively explained in terms of dispositional attributions. The teaching was thus not based on the curriculum or the syllabus which- as noted- was devoid of negative characteritics of the former enemy. The Othering of the Northerners in the teaching is best understood as an attempt of the teachers to maintain an exclusivist attitude towards the North and at the same time promote social cohesion and inclusiveness among the pupils of different ethnic groups in the same Southern classroom. As one teacher explained:

That ill feelings or hatred or distrust is still existing. Even though we are now two separate countries. ... Between the southerners and the northerners (Classroom observation, 2015).

Interestingly the current civil war was treated quite differently by the same teachers. The teachers did not openly discuss the ethnic tensions that took place outside the classroom, and rather downplayed the reasons for the current conflict. While the teachers explicitly taught about enemy images of the Other in the North the teaching about ethnic groups inside South Sudan and the current conflict did not contain any negative narratives. There "was a sense that conflicts between ethnic groups in the South after independence was a 'no go' area that did not fit the unified past narrative and collective memory which

\footnotetext{
${ }^{4}$ A new history book on South Sudan (Breidlid et al., revised edition 2014) was introduced after the start of the internal civil war to narrate the history from a South Sudanese perspective, but hardly any schools have received copies of it or have actually used it in the classrooms.
} 
the teachers followed in the classroom" (Skårås and Breidlid 2016, 111). The rationale behind being silent about conflicts inside the South can be interpreted as being due to the teachers' apparent efforts to create social cohesion and inclusion inside the classroom even though historical accuracy was sacrificed. In a sense the teachers created, at least superficially, social cohesion by focusing on coexistence between the multiple ethnic groups in the classroom as well as mutual respect and trust.

Despite the lack of narratives in the classroom of ethnic tensions during the current civil war tensions existed under the surface, among both students and teachers. When a student posed a question that required the teacher to touch upon the issue of ethnic tensions within the south, the teacher answered superficially and seemed to avoid the ethnic details (Classroom observation, 2014, 2015).

The question is however if such a strategy of avoidance really promoted social cohesion and peace since communication inside and outside the classroom differed dramatically.

In interviews done outside the classroom the teachers uttered opinions and told stories quite different from what they expressed inside the classroom. In the interviews, they were eager to characterize some of the ethnic groups (particularly the two biggest) in terms of dispositional attributions, not unlike how they characterized their Northern enemies (Skårås and Breidlid, 2016). The discrepancy between classroom teaching and what was said in interviews was most probably a conscious move by the teachers to suppress conflicts in classrooms with pupils of different ethnic backgrounds. Such an avoidance strategy obviously intended to contribute to peace building among the pupils by consciously promoting the ideas of positive relationships, solidarity and inclusion. While the ideas behind such a strategy were well-intended there is a sense that it could easily undermine a constructive and critical discussion of what could be done to address the conflict. To what extent did the teachers' behaviour inside the classroom foster values and attitudes that offer a basis for transforming conflict itself? Or did their avoidance of identifying and discussing internal conflicts in class in fact perpetuate and solidify perceptions of self and Others among the various pupils? In the context of the current civil war in South Sudan where the macro society does not ensure the welfare of all its members, does not minimise disparities and does not avoid polarisation, but rather increases social incohesion and conflict the teachers are up against formidable challenges since they have not been given any tools in the form of teacher training or peace building manuals that could have helped them to address conflicts in class. There were no structures in place to address in a pedagogical wise way tensions and divisions that were evident as soon as the pupils left the school buildings. As Sayed and Novelli state,

Improving social cohesion therefore requires addressing structural, inter-personal, and intergroup domains. In this sense, social cohesion can sometimes be used interchangeably with the concept of peacebuilding in conflict-affected contexts... (Sayed and Novelli, 2016, 35).

\section{Conclusion}

Teaching in a conflict-ridden nation often poses several challenges for the teacher, and it is not always easy to manoeuvre in such a complex terrain.

The above discussion has shown that teachers are not always promoters of peace and reconciliation, and that their teaching in class to a large extent is context-dependent. In some contexts there is little room for independent teacher manoevering whereas there in other contexts may be space for independent decisions, but where the 'right' decisions are difficult to find, even in terms of peace and reconciliation.

While the teachers in the Islamic schools during the first civil war had few options but to teach according to the Islamic curriculum and thus cemented the self-Other dichotomy in the conflict-ridden country the teachers in the liberation areas in the South chose deliberately a confrontation strategy against their oppressors from the North that coincided with the resistance war on the ground since the teachers and the pupils were, despite their different ethnic origin, in agreement about the struggle against the enemy of the North. The close affinity between the ideology in the classroom and on the battlefield posed few dilemmas: the classroom was in one sense an extension of the battlefield, being thus a site for an ideological and epistemological fight against the regime in the North and provided rhetorical support to the soldiers. Moreover the content of the syllabus was also in direct opposition to the pro-Arabic syllabus of the Islamic regime in the North even though it was not anti-Islamic. 
In the civil war inside South Sudan a different teaching pattern emerged where the teachers applied an avoidance strategy in class when teaching about the civil war inside the South, a somewhat problematic position since the same teachers had very clear opinions about the war and the warring parties in interviews outside the classroom. It was, however, perceived to be less of a dilemma to teach contemporary history without touching upon domestic conflict and ethnic rivalry than to teach about conflicts in the South which seriously undermined any idea of social cohesion. Undoubtedly the teachers felt strongly that it was necessary to treat history teaching carefully, and that "there is a fine line between what should and should not be told" (Skårås and Breidlid, 2016, 115). There was a sense that the reason why the teachers treated the North- South conflict differently from the current civil war in class was primarily due to the ethnic composition of the student population. Since the students originated from the various ethnic groups in South Sudan (also from the two major groups Dinka and Nuer) there was a perception among teachers that debating the domestic civil war might cause unrest and conflict in class whereas any discussion of the South-North war would not since very few, if any of the students had any allegiance to the North and the Islamic discourse.

The teachers' solutions to these dilemmas raise the question of education's role in conflict situations. Obviously, education can contribute to peace and reconciliation as well as instigate conflict (Sommers, 2002; Vriens 2004). The question is whether teachers can contribute to peace and reconciliation by not discussing the various aspects of the current civil war, or if another strategy where the war had been critically discussed would have served the promotion of peace and unity better. The teachers' different strategies in treating the North-South civil war (discussion) and the current South-South civil war (avoidance) might have been an attempt to achieve the same goal, viz. to try to solidify unity and social cohesion among the various student groups in the South.

Perhaps one should not exaggerate education's potential to play a reconciliatory role in the current conflict because of the poor state of the education system in the country with untrained and inexperienced teachers, a lack of the most essential textbooks (also in history), and over-full classrooms. The pedagogical challenges of teaching to a class of 100 pupils about ethnic grievances and conflicts cannot be overestimated. Even though there are moral dilemmas using an avoidance strategy in the current situation it seems from our material to be the teachers' preferred option. It means that the teachers primarily focus on teaching the basic skills and subjects to the pupils. Teaching about conflicts and ethnic rivalry as well as peace is relegated to periods in the past that do not directly affect the critical situation and lack of unity within the South today. Such a conclusion in fact entails a fairly pessimistic view of the role of the teacher as a contributor to reconciliation in the current context of civil war in South Sudan.

Acknowledgements. Special thanks go to my PhD student Merethe Skårås who did much of the field work during the current civil war in South Sudan.

\section{References}

1. Al-Bashir, M. (2004). "Basic Education: The Concept, Its Characteristics and Aims." Educational Studies: Journal of the National Council Curricula and Educational Research 5, no. 7 (June): 43-57 [in Arabic].

2. Breidlid, A. (2006). "Resistance and education - counter-hegemonic struggle in Southern Sudan Nordisk Pedagogik. Vol. 26, 16-29.

3. Breidlid, A. (2010). "Sudanese Images of the Other: Education and Conflict in Sudan." Comparative Education Review. Vol. 54, 555-579.

4. Breidlid, A. (2013). "The role of education in Sudan's civil war." Prospect. Quarterly Review of Comparative Education. Vol. 43. doi: 10.1007/s11125-012-9257-3

5. Breidlid, A., Androga Said, A. and Breidlid, A.K. (eds.) (2014). A Concise History of South Sudan. New and Revised Edition. Fountain Publishers, Kampala.

6. Bush, K. D. and Saltarelli, D. (2000). The Two Faces of Education in Ethnic Conflict. Towards a Peacebuilding Education for Children. UNICEF. Innocenti Research Centre, Florence.

7. Collier, P. (2006). Fragile States. Society for International Development: The Netherlands Chapter. Retrieved from www.sidnl.org/archive/lectures/2006_2007/SID_2006_2007_02_Collier.doc. 
8. CSCW [Centre for the Study of Civil War] (2011). Education and conflict: What the evidence says. CSCW Policy Brief 02/2011. PRIO, Oslo.

9. Davies, L. (2003) Education and Conflict. Complexity and Chaos. Routledge, London.

10. Education for All (2015). National Review Report: South Sudan. UNESCO, Paris.

11. Green, A, Janmaat, G. and Cheng, H. (2011). "Social Cohesion: Converging and Diverging Trends." National Institute Economic Review, Vol 215, Issue 1, 2011, 6-22.

12. Heider, F. (1958). The Psychology of Interpersonal Relations. Wiley, New York.

13. International Crisis Group (2014). South Sudan: A Civil War by Another Name. ICG, Brussels.

14. JAM [Joint Assessment Mission] (2005b). Volume 3. Cluster reports. http://www.unsudanig.org/docs/ Joint\%20Assessment\%20Mission\%20(JAM)\%20Volume\%20III.pdf (accessed on June 15 2018)

15. Jenson, J. (2002). "Identifying the Links: Social Cohesion and Culture." Canadian Journal of Communication. Vol. 27, No 2 , 141-151.

16. Kenyi, C. M. (1996). Report of a Survey of Educational Needs and Services for War Affected South Sudanese. AACC and Swedish Save the Children, Nairobi.

17. Lopes Vardoso, M. and May, A. (2009). Teaching for peace- overcoming division. In Nicolai, S. ed. Opportunities for Change. IIEP, UNESCO, Paris.

18. Maphalala, T. (2015). South Sudan celebrates its first comprehensive curriculum. [Web log comment]. Retrieved from http://www.globalpartnership.org/blog/south-sudan-celebrates-its-first-comprehensive-curriculum (accessed on October 25 2017)

19. McCracken, M. (1998). Social cohesion and macroeconomic performances. CSLS Conference on the State of Living Standards and the Quality of Life in Canada, Ottawa. Retrieved from http://www.csls.ca/events/ oct98/mccr.pdf. (accessed October 12, 2017).

20. McEvoy-Levy, S. (2006). Troublemakers or Peacemakers?Youth And Post-Accord Peace Building. University of Notre Dame Press, Notre Dame, Ind.

21. McLaren, P.L. (1995)" Collisions with Otherness; Travelling Theory, Postcolonial Criticism, and Politics of Ethnographic Practice- The Mission of the Wounded Ethnographer." In McLaren, P.L. and Giarelli, J.M (eds.). Critical Theory and Educational Research. State University of New York Press, New York, 271-300.

22. Novelli, M. and Sayed, Y. (2016). "Teachers as agents of sustainable peace, social cohesion and development: theory, practice \& evidence." Education as change, 20 (3). 15-37. ISSN 1682-3206

23. OCHA, United Nations Office for the Coordination of Humanitarian Affairs, September 2017. Washington DC.

24. O'Sullivan ,E., Morrell, A. and O'Connor, M.A. (eds.) (2002). Expanding the Boundaries of Transformative Learning. Palgrave, New York.

25. Oyenak, C.. (2006). "Multicultural Education in Support of Peace in the Sudan." HiO-report 2006, no. 3, University College, Oslo.

26. Paulson, J. (ed.) (2011). Education and Reconciliation: Exploring Conflict and Post-Conflict Situations. Continuum, London.

27. Reagan, T. G. (1996). Non-Western educational traditions: Alternative approaches to educational thought and practices. Lawrence Erlbaum Associates, Mahwah, NJ.

28. Salaam, A.H.A and de Waal, A. (2001). The Phoenix state: Civil society and the future of society. The Red Sea Press, Lawrence, NJ and Asmara.

29. Sayed, Y. and Novelli, M. (2016). " The Role of Teachers in Peacebuilding and Social Cohesion." The Research Consortium on Education and Peacebuilding. Universities of Amsterdam, Sussex and Ulster, 1-100.

30. Skårås, M. and Breidlid, A (2016). "Teaching the Violent Past in Secondary Schools in Newly Independent South Sudan." Education as Change Volume 20, Number 3, 98-118.

31. Skårås, M (2016). Focused Ethnographic Research on Teaching and Learning in Conflict Zones: History Education in South Sudan. Forum for Development Studies 45(2), 217-238.

32. Smith, A., and Vaux, T. (2003) Education, conflict, and international development. Department of International Development, London.

33. Smith, L. T. (1999). Decolonizing Methodologies: Research and Indigenous Peoples. Zed Books, London.

34. Sommers, M. (2002). "Children, Education and War: Reaching Education for All (EFA) Objectives in Countries Affected by Conflict." CPR Working Papers, Paper no. 1 World Bank, Washington, DC.

35. South Sudan Ministry of Education's 2011 Statistical Yearbook. (2010). Juba, South Sudan.

36. South Sudan Ministry of Education General Education Strategic Plan, 2012-2017. (2012). Juba, South Sudan. 
37. South Sudan Education Cluster (2016). Education Cannot Wait for the War to End. Retrieved from https://www.humanitarianresponse.info/system/files/documents/files/education_cannot_wait_for_the_war_t o_end___ssec___2017-06. pdf (accessed November 2, 2017).

38. Tawil, S. and Harley. A. (2004). Education, Conflict and Social Cohesion. UNESCO, Paris.

39. UNICEF (2014) UNICEF Annual Report 2014. Retrieved from https://www.unicef.org/publications/ index_82455.html (accessed on June 16 2018)

40. UNICEF. (2015). South Sudan, 8 September 2015: First-ever comprehensive national curriculum launched. Retrieved fromhttps://www.unicef.org/ esaro/5440_ss2015_national-curriculum.html on May 122019

41. UNICEF (2016), Reaching Children in South Sudan. Retrieved from https://www.unicef.org/infobycountry/ southsudan_74 (accessed on November 2 2017)

42. UNESCO (2013). Education for All Global Monitoring Report Policy Paper. Retrieved from http://unesdoc.unesco.org/images/0022/002216/221668E.pdf (accessed on January 2 2018)

43. Vriens, L. (2004). "Responsibility for the Future: The Key to Peace Education." In Peace Education in Europe. Wintersteiner,W,; Spaijic-Vrkas,V. and Teutsch, R. (eds.) Waxmann, New York, 71-84.

44. Weldon, G. (2010). History education and democracy in post-apartheid South Africa. The International Journal for Education Law and Policy, Special edition on Legitimation and stability of political systems. The contribution of national narratives, 88-103.

45. Wertsch, J.V. (2002). Voices of Collective Remembering. 1st edition. Cambridge University Press, Cambridge.

46. World Bank, The. (2012). Education in the Republic of South Sudan. Status and Challenges for a New System. Washington DC. 